\title{
An Aesthetic of the Unknown
}

\author{
Michael Evans
}

Department of Fine Art, University of Northampton, Northampton, UK

This paper begins to establish an 'aesthetic of the unknown' by drawing together theorists and approaches from mainstream art criticism to provide a starting-point for an aesthetic sympathetic with Jungian perspectives, in an attempt to bridge a gap between contemporary abstract painting, contemporary art theory, and Jungian studies. This is a framework for approaching abstract painting not as an object awaiting interpretation or 'reading', but rather as something that offers a numinous experience (or experience of the unknown), which can be thought about but may remain ultimately unknowable and irreducible. Such experience - involving both the unconscious and conscious mind - would provide glimpses of forms of meaning not accessible to full rational exposition. This type of unconsciously understood meaning is explored, acknowledging that there is a need to preserve this encounter with the unknown and a need for a contemporary critical, theoretical framework that recognizes the importance of this within abstract painting.

\section{key words}

Abstract Painting, Spiritual, Apophatic, Numinous, Unknowable

A particular type of abstract painting, I would suggest, can provide us with an experience of the unknown. Terms such as the numinous, the spiritual or the sublime, have long been associated with the works of abstract painters such as Wassily Kandinsky, Piet Mondrian, Mark Rothko, Barnett Newman and Ad Reinhardt, with the possibility of extending this to include current painters such as Gerhard Richter and lan McKeever who will be discussed later. Although it may be possible to view these terms as separate experiences with clear and distinct theoretical discourses, they could also be seen to refer to types of wordless experience and to aspects of an unknown which may involve significant areas of common experience. Such experience involving both the unconscious and conscious mind without being fully understood, would provide glimpses of forms of meaning not accessible to full rational exposition. This type of unconsciously understood meaning shall be explored here, with a recognition that there is a need to preserve this encounter with the unknown and a need for a contemporary critical, theoretical framework acknowledging the importance of this area of experience within abstract painting. This 
piece begins to establish an 'aesthetic of the unknown' drawing together theorists and approaches from mainstream art criticism to provide a starting point sympathetic with Jungian perspectives, in an attempt to bridge a gap between contemporary abstract painting, contemporary art theory and Jungian studies.

There are significant art theorists who have recognised the importance of this area of experience, however, often these approaches come from Freudian or post-Freudian derived positions. Here aesthetic experience, spiritual experience or any form of transcendent experience is seen as a comforting illusion, a consolation, which helps us deal with a brutish and unsatisfactory reality. Looking at art theorists such as Peter Fuller and Donald Kuspit it is possible to see where a Jungian influenced aesthetics of painting could make an important contribution based on a more positive model of the psyche and the role of creative and artistic practice. Here I will attempt to bring together some of these disparate approaches from art theory and to reframe and synthesise these thinkers into a less reductive and more positive framework. I hope to demonstrate that within these diverse frameworks, in a variety of forms and with a shifting nomenclature, there lies a wide reaching interest in what may be described as the unknown, the numinous or the spiritual in abstract painting. In attempting this I am hoping to end this piece at the position of a starting point where a Jungian influenced critique of abstract painting could begin.

\section{The Unconscious}

The role of the unconscious is vital in understanding the territory of the unknown within abstract painting. In concepts such as the symbol and the archetype - and his emphasis on the importance of the numinous - Jung provides a positive and progressive view of the unconscious and our relationship with the symbolic which hints at 'that which is not yet known' (Jung, 1978, p41). Such concepts could provide a sympathetic framework through which abstract painting concerned with an experience of the unknown could be understood. However, with the notable exceptions of modernist painters such as Jackson Pollock or the British abstract painter Alan Davie; the influence of Jungian ideas on both contemporary painting in both practice and theory remains marginal. The following is an attempt to understand abstract painting as a way of bringing us into contact with the unknown via a particular type of aesthetic experience found within painting and understood within a conceptual framework that can be described as apophatic.

The contemporary art world struggles with the word spiritual, the term transcendental is less than fashionable and even the unconscious 
cannot be taken for granted as an important part of art making. Critic Donald Kuspit is clearly concerned warning,
Without the unconscious for inspiration, art begins to run on empty, which is what much of it is running on today. The belief that the unconscious is a social construction - a bourgeois ideology - is an attack on it.
(Kuspit, 2004, p.105)

The home of spiritual or numinous experience once in religious art could be viewed as having become a vestigial trace of the religious within nature via the romantic sublime. Similarly increasing importance came to be placed on the human imagination as a site of divine inspiration for artistic production. An increasing emphasis on the self continued through Expressionism and may be seen to reach a climax in Abstract Expressionism. At this point the self could be understood as also having a vital connection to the unconscious. However, even these have been called into question by postmodernism, deconstructionism and the ongoing forces of a rationalist, secular culture. These changes would seem to represent an increasing secularisation in the preferred language of discourse around art and it seems whatever home these feelings find is gradually shut down. Writer Sean Burke brings an interesting perspective to this sense of 'shutting down' viewing the 'death of the author' as having similarities to 'the death of God'.

The death of the author might be said to fulfill much the same function in our day as did the death of God for late nineteenth-century thought. Both deaths attest to a departure of belief in authority, presence, intention, omniscience and creativity. For a culture which thinks itself to have come too late for the Gods or for their extermination, the figures of the author and the human subject are said to fill the theological void, to take up the role of ensuring meaning in the absence of metaphysical certainties. The author has thus become the object of a residual antitheology

(Burke, 1992, pp.22/23)

This position can be further complicated if one does not put such emphasis on authorship in the production of artworks but reveals the extent to which certain previously important beliefs concerning the creative process have come into question. From a Jungian perspective, the issue is seen as a fundamental problem with the numinous itself by David Tacey, who says

As soon as anyone touches on the numinous, a kind of spiritual complex is triggered in the culture, which immediately sets up a resistance. Jung said 'the gods have 
become diseases'.... and they are treated by the modern ego like pathogens in the body. The ego's anxiety triggers an automatic defence reaction, activating forces of resistance. As with any unconscious complex, the spiritual complex is triggered automatically and is hard to detect.

(Tacey in Casement and Tacey, 2006, p.219)

Critics such as Kuspit would argue that within contemporary art there has been a steady movement away from an emphasis on the unconscious, which in turn means that any type of art relying on the unconscious will struggle for critical acceptance or attention. This could be seen as an example of Tacey's 'spiritual complex'. Even if we do not go so far as this there is still the concern with what will happen to art if the unconscious is no longer seen as a prime source of creativity. For Kuspit this turn away from the unconscious is damaging, he described art that abandons the unconscious as 'post-art' warning,

For unless the profound influence of the unconscious on modern art is understood, one cannot begin to understand the depth and credibility art in general lost when it forsook the unconscious...Post-art looks to ideology and, more broadly, theory for a foundation - and significance - and attacks the unconscious by reducing it to an ideology, more particularly, a phenomena of bourgeois society...Dreams are trivialized and feelings dismissed - subjectivity as a whole is demeaned.

(Kuspit, 2004, pp.90/91)

Another problem is the tendency in postmodern and deconstructionist practices for the artwork to be treated as a 'text' to be 'read'. Within semiotic schools of thought the artwork becomes a set of signs to be decoded, reconfigured, understood and ultimately reduced. Art theorist James Elkins worries that semiotics has had the unfortunate effect of 'bringing visual narratives unpleasantly close to written ones...semiotics shrinks the notion of what a picture is, assimilating pictures to texts and overlooking their painted strangeness' (Elkins, 1998, p.5). Elkins is suggesting the idea of 'staying with' a painting, of attending fully to the object. This may sound obvious or easy but many attempts to describe or understand paintings can move very quickly past the painting as a unique object into a set of interconnected references or into a discussion of how a painting may operate within a given interpretative system e.g. psychoanalytical, semiotic, historical etc.

it is hard just to look: it is much easier to read, or to tell stories, than to stare at the peculiarities of a stubbornly 
silent and senselessly wordless object [...] I am attracted by the remnants of pictures - whatever resists interpretation or remains unaddressed or unexplained.

(Elkins, 1998, p.267)

Elkins is not arguing for muteness as a response to the "wordless object' but rather a respect for its difference from the spoken or written word and sounding a cautionary note concerning the diminishing of it by simply placing it within an interpretative system. Kuspit warns against the temptation to understand or make sense of much modern art and suggests rather that the apparent 'unintelligibility' of such art is in fact a vital component. This is a key point in constructing an aesthetics of the unknown as we first have to recognise the importance of the 'unintelligible' and that this is not merely something which awaits understanding. Kuspit understands that to entirely explain the work of many key modern artists would be a negative factor, telling us

if their works were to lose that sense of keeping a secret that makes them mysterious, and lapse into the banality of outspokenness, they would instantly seem insignificant. There is much pressure to trivialise them into obvious meaning - to explain their mystery - because the inclination to enigma is generally suspect in the modern world, which is determined to be clear and distinct (Kuspit, 1994, p.114)

Kuspit is also correct in viewing this as part of a larger problem of the 'modern world' and its suspicion of enigma. We have seen from a number of sources that the numinous, the spiritual, the unknown or the unintelligible can often have an uneasy relationship with interpretive systems operating within a largely secular, rationalist culture. There could be said to exist a tension concerning whether many interpretative systems are capable of allowing the artwork the necessary sense of autonomy (and I would add dignity) to exist in a state of mystery or unintelligibility as for many systems meaning is something to be analysed and understood. Painter lan McKeever puts it well when he tells us 'Paintings are not tools for learning, but redemptive moments in our lives' (McKeever, 2005, p.94).

At this point we need look back to the specific object of the abstract painting to ask how it may communicate meaning. The abstract painting may be stripped of image and narrative so these are not the methods by which it communicates its peculiar type of meaning. This is where we need to be attentive to the object for it is through its formal characteristics and attributes that the abstract painting may generate meaning. Caution is needed at this point as abstract painting; which has aspired to the depth (or height) of numinous experience has 
not benefitted greatly in the past from formalist critique. Clement Greenberg, the most famous exponent of a formalist critique of abstract painting (as Kuspit has pointed out on more than one occasion) privileged the material and aesthetic nature of painting at the expense of other key aspects. There is no room for anything approaching a spiritual or numinous dimension and even notions of expression and its relationship with the unconscious fail to make much of an impact on Greenberg's brand of formalist critique. Kuspit is very clear over the importance of this omission saying,

in my opinion the most important aspect of Greenberg's modernism is his distinction between art's literal order of effects and its preconscious and unconscious order of effects, and the elevation of the former and the dismissal of the latter as incoherent and inherently difficult to pin down, name - make intelligible...[it]...is one of the great crimes perpetrated upon modern art [...] We must look for the depth in the unintelligible.

(Kuspit, 1994, pp.116/117)

So the task is to avoid a demeaning and reductive form of interpretative system and to be attentive to the specific physical, formal and aesthetic qualities of the painting without becoming mired in another form of reductive thinking such as Greenbergian type formalism. What is needed is an acknowledgment of the physical, formal and aesthetic nature of the abstract painting but alongside an understanding of the importance of how this is inextricably linked to the unconscious, the unknown or the unintelligible. Kuspit has coined the word 'psychoformalism' in order to acknowledge both aspects of the task required for an adequate reading of a painting. He describes it thus,

In examining the effects of the cultural product on himself or herself, the analyst-critic must move from an interpretation of its subject matter to an interpretation of its form [...] The failure of applied psychoanalysis is that it has not yet become an adequate psychoformalism (Kuspit, 1994, p.329)

This is an important step in uniting two key approaches towards understanding abstract painting. Kuspit has placed the physical and aesthetic attributes of the painting at the heart of his interpretation but (and this is the vital distinction) not as a straightforward demonstration of materiality. Rather, this materiality is inextricably bound to the inner life of both painter and viewer and there is recognition of the importance of the unconscious or preconscious elements of the artwork. The place where we part company with Kuspit is not over the recognition of the task which needs to be undertaken but rather over the psychological aspect of his critique, informed as it 
is by a form of Freudian or post-Freudian psychological world view. This leads to a view of aesthetic experience as a form of consolation rather than seeing aesthetic experience (and other forms of transcendent experience) as possibly 'higher' functions capable of emerging from a more positive world view and model of the psyche, which would be capable of much more than just moments of consolation. It is not too difficult to see how this could be supported if one were to apply a more Jungian outlook.

Peter Fuller and Donald Kuspit frequently refer to abstract art and profound aesthetic experience as being an illusion, albeit a necessary one for both. However, if one accepts that Jungian thought may be able to provide a more optimistic psychological framework it may then be useful to return to some of the key ideas of both writers but with the knowledge that although much of their method may be useful the underlying psychological premises do not necessarily need to be shared. This said, Peter Fuller made a significant contribution to what Kuspit calls the 'psychoformalist' approach with his ideas regarding the importance of the aesthetic emotion as being beyond a simple pleasurable, formal experience and this is where we turn next.

\section{The Aesthetic Emotion}

By looking at the idea of the aesthetic emotion as used by art theorist and critic Peter Fuller we can begin to better understand what sort of experience we are attempting to articulate and to establish how it operates on a psychoformal level. It is important that this definition grows from within art rather than emerging from another form of discourse, as we can then begin to understand the type of experience we may be encountering in an artwork and how this takes place. Similarities with psychological and theological ideas become apparent but importantly we are looking at properties of the artwork and not immediately beyond it. As with Kuspit, Fuller is perceptive in identifying aspects of the aesthetic emotion, allowing them to be considered with an appropriate level of depth alongside mystical, numinous and spiritual experience. Again as with Kuspit, we learn much from Fuller but we need to move beyond him when his original psychological premises will not allow him to move beyond a model of the infant, the primary process and ultimately art as a form of consolation.

Fuller is clear in establishing the level of experience we are considering with the aesthetic emotion, it has much in common with aspects of religious and numinous experience although it means something different for Fuller than it did for Clive Bell who was the original source of the term. In Art \& Psychoanalysis Fuller goes to great lengths to understand his own profound aesthetic experiences. 
He sees psychoanalysis as a modern, materialist method of investigation, into not only the aesthetic emotion but also the sublime, the numinous and religious or mystical experience in general. It is significant that his explanation of a profound or numinous experience of art is also his explanation of religious experience.

'Significant form' was a term coined by Clive Bell and denoted the importance of certain formal attributes of an artwork e.g. line, colour, surface etc. For Bell and fellow writer Roger Fry formal qualities of the artwork give rise to the 'aesthetic emotion'. These significant formal qualities point beyond mere pleasure as Fuller points out,
Although Fry and Clive Bell gave primary attention to the visual, they did not think [...] that the question of value in art could be reduced to sensation, form and pleasure. Rather, they seem to have believed that those combinations of colours and lines which gave rise to aesthetic emotion provided an avenue to spiritual experience of a kind which the imitation of nature could not. (Fuller, 1983, p.157)

So significant form gives rise to something like a spiritual experience, which is the aesthetic emotion. In order to clarify what is meant by the aesthetic emotion we must look to Clive Bell, from whom Fuller quotes a passage in which he compares the rapture of the highest forms of aesthetic experience with a simpler enjoyment of line, colour etc. Bell tells us that to simply enjoy painting as a pleasurable experience should not be a source of guilt but warns against confusing this with what the aesthetic emotion entails, which he describes as 'the cold, white peaks of art' (Bell, in Fuller, 1983, p.149). This emotion Bell feels is far from a commonplace appreciation, and sounds similar to a description of feelings associated with the sublime or the numinous. If this seems to rather stretch the point then we can continue to explore Bell's ideas on art and there is no mistaking the spiritual or religious dimension. Bell tells us
art and religion belong to the same world. Both are bodies in which men try to capture and keep alive their shyest and most ethereal conceptions. (Bell, in Fuller, 1983, p.148)

So the importance of the aesthetic emotion becomes clear, Bell sees it as a form of religious experience. Perhaps one of the most interesting comments he went on to make was to again compare art to religion but going even further concerning the similarities of the emotion involved. This suggests it is this emotion which is at the heart of both art and all religions. Bell tells us that the aesthetic emotion is 
an expression of that emotion which is the vital force in every religion... We may say that art and religion are manifestations of man's religious sense (Bell, in Fuller, 1983, p.148)

We can see how close this is to Rudolf Otto's ideas concerning the numinous as Otto had little doubt that there was a numinous core to all religion. In The Idea of the Holy (1917) as he works towards his introduction of the category of the numinous he refers to 'this unnamed Something' and leaves us in no doubt as to its importance saying,

There is no religion in which it does not live as the real innermost core, and without it no religion would be worthy of its name.

(Otto, 1953, p.20)

The comparison here is striking. Both Bell and Otto are convinced of an underlying and we may add unfathomable and irreducible experience, which for Otto defines a vital core of religious experience and for Bell, Fry and Fuller in his own way, also defines a certain type of aesthetic experience which in one sense could also be seen as a form of religious experience.

With an understanding of the importance the role of significant form in painting may have, along with an understanding of the depth of experience implied by the term aesthetic emotion and how close these may come to both religious and numinous experience, we can return to the artwork in its material sense. For we now can see that through its very materiality and formal constitution the painting can engage us in a profoundly significant manner. For Fuller painting is tied to its material qualities and it is through these material qualities that access to this particular aesthetic realm in gained. Although it may seem perverse for an exploration of abstract painting, one of the most helpful passages of Fuller's writing concerns a description of the representational works of the expressionist painter Chaim Soutine. In this passage he attempts to understand how the physical quality of the painting itself may be affecting him.

Even when the subject matter is morbid, or downright ugly, a good Soutine picture commands, not sickening revulsion, but rather a giddy exhilaration, a sense of relish in the possibilities of life [...] Indeed, he seems to be trying to compel inner and outer to congeal in an opalescent skin of viscous paint; he wants something different from illusion. In its opulence of colour, its physicality, its rhythmic ordering, the picture strains towards an actuality all of its own. It bears witness to a secular sense of re-ligion (or re-binding): a kind 
of healing fusion in which tortured self and degraded world are both merged and surpassed through the redeeming power of form. And it is this 'new reality' within the picture which we find exalting - regardless of the artist's angst, or the tawdriness of what is shown.

(Fuller, 1990, pp.51/52/53)

The power of Soutine's paintings lies not in subject matter but in the 'redeeming power of form'. However, this of course does not mean that all painting simply gains access to these deeper levels of meaning merely by virtue of its having been made with paint. As Fuller points out,

Paint itself is not a magical or fetishistic substance whose mere application endows special qualities. Paint demands profound transformation through imaginative and physical working (Fuller, 1990, p.9)

So although painting provides the opportunity for aesthetic emotion it can only be arrived at through 'profound transformation' this though does not necessarily mean that any of this process is tied to a representational image. What is perhaps of most significance for abstract painting in this instance is that the success of the Soutine painting can contradict the image and this leads to the conclusion that the image is not necessarily the most important factor. If one takes this imaginative leap then it could be claimed that the image is in fact, not necessarily needed at all in this equation and that what is important is the 'profound transformation' found in the 'redeeming power of form' - the paint. It may even be that at this point abstraction can confront the viewer with a more direct experience of 'redemption through form' and the imaginative and physical working of paint, if the distractions of image and narrative and of the need for this sort of interpretation are removed. This forces both the artist and viewer to engage more directly with the painting, which may not necessarily be an entirely comfortable experience.

The next step for Fuller was to attempt to understand and describe how this process worked and certain parts of the above text on Soutine are key here. It is important for Fuller that there is a merging of 'inner and outer' in painting. He goes on to state that this involves 'a kind of healing fusion in which tortured self and degraded world are both merged and surpassed through the redeeming power of form' and this gives an insight into the limitation of Fuller's position. Again we see that Fuller is similar to Kuspit; with art ultimately seen as a form of consolation for either, unbearable aspects of the self and/or world. Similarly religion is seen by both as an illusion but a necessary 
illusion, helping us to cope with the awfulness of reality. So we part company with Fuller as he comes to the conclusion that the fusion of inner and outer in painting meant that it became a kind of transitional object and an exploration of the 'potential space' established during early infancy as proposed by D.W. Winnicott. All feelings of transcendence or unity were welcome illusions, which resonate with us due to infant experiences of oneness with the mother and which help compensate for our negative experience of reality. However, for those who do not share this view of reality or feel that this in some way diminishes the experience of art in its most profound sense we can at least take what Fuller has established concerning the aesthetic emotion, significant form and the importance of the material aspect of painting. This again is where a Jungian inspired aesthetics could contribute significantly to shift the emphasis away from the idea of any spiritual or numinous qualities being only an illusion or consolation, locating these qualities instead within a more positive view of the unconscious and giving them the dignity to be of help in the growth of the subject.

A similar emphasis on the materiality and processes of painting can be found in James Elkins most notably in What Painting Is (2000). Again as with Fuller, Elkins is happy to discuss painting and spiritual experience side by side which is something he has observed many in the contemporary art world are unable to countenance. However, James Elkins does not approach painting from the same perspective as Fuller and he is more open to seeing what painting may offer on its own terms.

Painting is an unspoken and largely uncognized dialogue, where paint speaks silently in masses and colours and the artist responds in moods [...] Painters can sense those motions in the paint even before they notice what the paintings are about. Paint is water and stone, and it is also liquid thought.

(Elkins, 2000, p.5)

The notion of paint as 'liquid thought' is an interesting one and seemingly contradictory. In the process of its making the painting is at times liquid thought as the painter may work beyond the control of the conscious mind, acting so quickly that only intuitive response is possible. However, this is also balanced by periods of consideration, what may be called retrospective analysis, where an artist just as much as a viewer may struggle to understand what has taken place. The painter, Elkins tells us, does not start from the position of always being in control.

Artists cannot begin in antiseptic abstraction, like philosophers with their notepads, or theoretical physicists at 
their blackboards. They have to begin in media res, literally in the middle of things: oil, canvas, squalor.

(Elkins, 2000, p.72)

To which it could be added that the experienced painter does in fact understand, and perhaps even seeks the experience of not being in control. This embrace of being out of control, of being a channel for something, rather than being the sole author should not be underestimated. Of course it must be noted that this only refers to a certain type of painting, however, for the type of painting and the type of experience being considered, Elkins provides an appropriate description. He articulates how the substance of the painting may come to act upon the viewer but without recourse to the somewhat restrictive model of Fuller and begins to touch on one of the aspects which may make painting so enduring in its appeal in an age of so many other possibilities for art making. In its very stillness lies the strength of the painting, a stillness that strangely allows more time, a time for the viewer to interact with the painting and for the imagination to work with or upon the painting. Elkins tells us

Imagination is fluid, or it wants to be, and the very act of painting is an act of violence against the liquidity of our thoughts [...] That is one of paintings powers, since the stillness of painting can reflect in ways that volatile arts, such as movies and plays, cannot. A film bombards the senses with new configurations, while a painting remains still, waiting for us to dream the changes it might possess. (Elkins, 2000, p.124)

There is an openness concerning the approach of Elkins not present in Fuller. With Elkins we start with what the painting can teach us, there seems to be a greater importance attached to the interaction of the painting and the imagination via the manipulation of a substance, the paint itself. The liquid thought referred to earlier by Elkins even once it has become static would seem to be able to act upon the imagination which in turn becomes fluid. Where Elkins does share some similarities with Fuller is in the use of the term hypostasis when referring to painting. This is significant given the religious usage of the word and perhaps this is a more helpful way of thinking how we may interact with painting.

There is a word, hypostasis [...] Properly speaking, it is a religious concept [...] A hypostasis is a descent from an incorporeal state into ordinary matter, or in general an infusion of spirit into something inert [...] it can explain the notion that two fluids, mingling in a bottle or on a canvas, are somehow expressing a state of mind [...] that something 
as dead as paint might also be deeply alive, full of thought and expressive meaning.

(Elkins, 2000, p.44)

So from one perspective paint then can be seen as a kind of conduit for meaning, both between painter and painting but also between the painter, painting and audience. This could be viewed in different ways with painting being a conduit for a meaning, which somehow lies beyond painting, or being the source from which meaning emerges. Again, a Jungian contribution at this point could reconcile the source of this meaning as coming from the unconscious - we may speculate both from the unconscious of the painter, having made the painting, which is felt to embody meaning albeit unintelligible, but also from the unconscious of the viewer, who again may experience meaning within the painting but interestingly from the interaction of what is presented and what the viewer intuits from this.

\section{Problems - Transformation or Simulation}

All that has been said so far is highly celebratory of the possibilities of painting. It is important to remember painting has undergone many attacks within the art world and has been pronounced dead a number of times. In response to this, painting has adapted, changed and assimilated at various stages in its more recent history. Often it has been laced with irony and reference, which could be seen as a form of defence, never more so than in the 1980's and early 1990's with ironic referencing of other art becoming highly fashionable with painters such as Peter Halley or Phillip Taaffe referencing Piet Mondrian and Barnett Newman. The problem now exists of how to make paintings which have a true sense of discovery about them rather than merely referencing other painting. There are two approaches to the spiritual in painting outlined in Donald Kuspit's essay Concerning the Spiritual in Contemporary Art in Maurice Tuchman's The Spiritual in Art: Abstract Painting 1890-1985 and both encounter difficulties in terms of finding new or fresh ways to pursue them. There is not the space to explore this in depth here but he suggests the categories of silence and alchemy. In terms of what Kuspit means by alchemy we can take this as meaning the physical and material nature of the painting (as has been discussed) and as for silence this is the reduced, minimal type of painting exemplified by painters such as Mark Rothko, Barnett Newman, Ad Reinhardt or Agnes Martin who all approach emptiness. Both these approaches have significant traditions but both also come up against the same problem of overfamiliarity and of becoming stuck in a chain of referentiality, which denies the necessary primacy of experience in approaches to the unknown or numinous. When a seemingly spontaneous or genuinely unfamiliar method of painting becomes a recognised style can it really claim to emerge from any sort of collaboration with the unconscious? Timo Valjakka art critic and 
theorist put the dilemma for the contemporary painter well when he said

The question is: how does one proceed in a situation where virtually all gestures and marks have been used, becoming inscribed into the long history of painting? How should one spread paint on the canvas to ensure that the spectator sees the painting as it is, and not just as a web of references, quotations and pre-existing meanings? (Valjakka, in McKeever, 1996, p.16)

This is the problem for the physical, material or 'alchemical' painter who relies on the painted gesture or physicality of the painting and for the minimal, 'silent' painter it proves just as difficult with Kuspit informing us that

The problem is how to create essential silence in abstract art today. Abstract art must pursue ever more complicated ways of becoming silent... Touch itself exists under enormous constraint; it often becomes increasingly inhibited (Kuspit, in Tuchman, 1986, pp.314/315)

So regardless of approach this is the problem facing the contemporary abstract painter. How to engage in an authentic imaginative process of transformation and not end up merely creating a simulation of previous abstraction? The answer is perhaps not to regard these two approaches as being completely exclusive. Even the overtly physical, material painting can be devoid of recognisable form and the silent eroded painting is still a material object even emptied of form. What the two may share when successful, is a sense of strangeness, unfamiliarity or unintelligibility. Granted these appear two opposite approaches but in this sense they rely on something similar. It is this 'unknown Something' (to refer back to Otto) which these approaches may share which will be explored in this last section.

\section{An Aesthetic of the Unknown - Apophatic discourse, Painting and Numinous Experience}

When Kandinsky and Mondrian first used abstraction for their own spiritual purposes their respective approaches were radical, new and strange. Now of course not only Kandinsky and Mondrian are familiar but also the abstract painting of Rothko and Newman. This leads to the conclusion that it is not simply the substance of paint that is transporting no matter its physical intensity or the daring subtlety of an approach to emptiness. I would contend that it is the strangeness, the nature of feeling in new territory, of feeling lost and unfamiliar in a painting that is the important factor in both these approaches. This should not be confused with novelty, which can merely be a variation 
on the already known. Kuspit made clear the distinction between the true goals of authentic avant-garde art and what he would call a 'pseudo avant-garde' which seeks a feeling of being contemporary, of novelty or newness in its most shallow form and this suggests that without the element of the unfamiliar an approach towards the unknown or numinous experience would be impossible. He warns about the danger of staying with the already known, and how it may be essential to keep changing the method of achieving the numinous potential of the artwork, saying

It is easy to backslide to intelligible art, and art that was once recognized as enigmatic can be regarded as unenigmatic banal - when it becomes habitual. Overfamiliarity even dulls the edge of mystery.

(Kuspit, 1994, p.114)

This means that new ways have to be found to access feelings or areas of experience which older forms of abstraction have previously been able to enjoy. Here the painter's task again becomes clear. Every painter has, in a way, to begin again in a quest to find their own path towards the unintelligible, enigmatic or numinous, while attempting to avoid the habitual or overfamiliar. However, painters are not alone in their interest in the unknown, unintelligible or numinous. There exists a great tradition of religious thought within negative theology dealing with what lies beyond the power of rational and verbal expression. Jung took a keen interest in the work of religious thinkers such as Meister Eckhart and undoubtedly appreciated the significance of their thought for the development of his psychology (Jung, 1970). For Eckhart and the Christian mystics this great unknowable source of meaning was God, the negative theologian would assert that God is unknowable and beyond human comprehension. However, for all the contradiction inherent in its method, negative theology does continually take us to one clear point and that is, an understanding of the limitations of the rational mind and our ability to consciously grasp certain forms of meaning.

If one looks at what could be described as the method of reasoning in negative theology we encounter apophasis. If we were to move slightly beyond the discussion of negative theology and concentrate instead on the apophatic attitude, I would suggest this is the mode of discourse which best serves contemporary abstract painting, which aspires towards the numinous or spiritual through an encounter with the unknown. There is not space here to fully do justice to apophatic thought, which ranges across many forms of discourse and is not necessarily theological in nature. For the purposes of this piece the importance aspect of an apophatic attitude is in establishing forms of meaning emerging beyond or prior to language and from an unknown or unknowable source. William Franke describes apophasis in his 
excellent two-part history of apophatic thought On What Cannot Be Said. (2007),

In apophasis, strictly construed, unsayability or the failure of language is itself basic to the experience [...] And yet the experience in question is not fundamentally experience of language or of any other determinate object, for this could be adequately expressed. The experiencing subject is affected by "something" beyond all that it can objectively comprehend, something engendering affects that it cannot account for nor even be sure are its own. This entails a sort of belief in, or an openness to, something - that is, or other that is surely no thing - that cannot be said and that refuses itself to every desire for expression.

(Franke, 2007 p3)

It is this ability to accept the limitations of language and of rational thought and to be able to accept paradox and contradiction, which is shared by certain key contemporary artists. Let us briefly look at how two contemporary painters describe abstract painting. First Gerhard Richter, who is one of the most significant painters of the last 50 years. Richter tells us,
Abstract pictures [...] make visible a reality that we can neither see nor describe, but whose existence we can postulate. We denote this reality in negative terms: the unknown, the incomprehensible, the infinite. And for thousands of years we have been depicting it through images such as heaven and hell, gods and devils. In abstract painting we have found a better way of gaining access to the unvisualizable, the incomprehensible; because abstract painting deploys the utmost visual immediacy - all the resources of art, in fact - in order to depict 'nothing' [...] the unvisualizable: that which has never been seen before and is not visible. This is not some abstruse game but a matter of sheer necessity: the unknown simultaneously alarms us and fills us with hope (Richter, 1993, p.100)

Richter uses the term 'unknown' and acknowledges it may both alarm and give us hope. He has made many comments comparing art with religion but the majority of critical texts within the fine art world touch on this only rarely and even then briefly. He has gone as far as to say, 'To believe, one must have lost God; to paint, one must have lost art.' (Richter,1993. p.15). This has strong echoes of negative theology and its contradictory use of internal denial and Richter could be said to be strongly apophatic in his thought. Similarly, the British abstract painter Ian McKeever demonstrates an awareness of and interest in the importance of the unknown, 
Our society and our culture are increasingly predicated on the supposedly known [...] In painting a painting one does not set out to paint what one knows, but rather tries to touch those things which one does not know and which perhaps cannot be known. Implicit in the unknown and what we cannot know about paintings, is a stillness and a silence. Our lives are now flooded with images which remorselessly bombard us with what we 'should' know, and which steal our time. Perhaps one of the things which paintings can do for us, if we are prepared to be still in front of them, is to give us back our own sense of time and the independence which goes with it.

(McKeever, 2005, p.61)

In both these painters there is a sense of understanding the importance of the unknown and of embracing it, this is also true within negative theology and was also understood by Jung. Although Jung didn't focus his attention on abstract painting and did not live to see the work of either of the artists I have cited this does not matter. For the construction of a Jungian aesthetics for abstract painting, I would suggest we should look at what are the deepest motivations of the type of painting discussed here. This means looking at the numinous and the unknown and this we find is central to Jung's work. His interest in mysticism and the numinous are highly relevant when considering transcendentally motivated painting. John Dourley has written eloquently on Jung and mysticism and I turn to a particular essay Jung, some Mystics and the Void where he indicates that there is still room for further investigation concerning Jung's relationship to mystics such as Eckhart and 'the possibility that they surfaced a psychic depth left largely undefined but highly appreciated by Jung himself.' (Dourley, in Ashton, 2007, p.52)

What Dourley points out as Jung's hugely important contribution in this area of thought is his recognition of the central importance of the numinous telling us that

The experience of the numinous is at the heart of mystical experience, and Jung rightly extended the sense of the numinous to the experience of the gnostics, alchemists, and seekers after the Grail. He argues throughout his work that the sensitivity to the numinous shared by these neglected traditions of the Western spirit is really the major, if not the only, resource in a specifically Jungian approach to therapeutic transformation. (Dourley, in Ashton, 2007, p.73) 
I would like to further extend the sense of the numinous to abstract painting and to end with a beginning of sorts. This piece of writing has gathered together some disparate areas of writing, which although they have emerged outside of Jungian dialogues could be of use in the construction of a Jungian influenced aesthetics. This is a framework for approaching abstract painting not as an object awaiting interpretation or 'reading' but rather as something which offers a numinous experience (or experience of the unknown) which can be thought about but which may remain ultimately unknowable and irreducible and would be all the more valuable because of this. I will finish then with the words of George Steiner and his observation that 'Representation is an inventory of the choices made, whereas abstraction narrates the abyss of total freedom which preceded and contained these choices.' (Steiner, 2002, p.115)

\section{References/Bibliography}

Ashton, P. W, (2007), From The Brink (Experiences of the Void from a Depth Psychology Perspective), London: Karnac Books.

Burke, S. (1992), The Death and Return of the Author (Criticism and Subjectivity in Barthes, Foucault and Derrida), Edinburgh: Edinburgh University Press.

Casement, A, and Tacey, D (Eds), (2006), The Idea of the Numinous (Contemporary Jungian and Psychoanalytical Perspectives), London and New York: Routledge.

Elkins, J. (1998), On Pictures and the Words that Fail Them, Cambridge: Cambridge University Press.

Elkins, J. (2000), What Painting Is, New York/London: Routledge.

Franke, W. (Ed), (2007), On What Cannot Be Said (Apophatic Discourses in Philosophy, Religion, Literature, and the Arts) Volume 2 Modern and Contemporary Transformations, Notre Dame, Indiana: University of Notre Dame Press.

Fuller, P, (1983), Art and Psychoanalysis, London: Writers and Readers.

Fuller, P, (1990), Images of God (The Consolations of Lost Illusions), London: Hogarth Press.

Jung, C. G. \& Adler, G, (Ed), (1970), Psychology and Religion, The Collected Works. Vol.11. London: Routledge 
Jung, C. G. \& von Franz M.L. (1978), Man and his Symbols, London: Picador

Kuspit, D, (1994), Signs Of Psyche in Modern and Postmodern Art, Cambridge: Cambridge University Press.

Kuspit, D. (2004), The End Of Art, Cambridge: Cambridge University Press.

McKeever, I. (2005), In Praise of Painting, Brighton: Centre for Contemporary Visual Arts/University of Brighton.

Otto, R, (1959), The Idea of the Holy, London/Harmondsworth: Pelican Books.

Richter, G, (1995), The Daily Practice of Painting (Writings 1962-1993), London: Thames and Hudson/Anthony d'Offay.

Steiner, G, (1991), Real Presence, Chicago/London: University of Chicago/Faber and Faber.

Steiner, G, (2002), Grammars of Creation, London: Faber and Faber.

Tuchman, M, (1986), The Spiritual in Art: Abstract Painting 18901985, New York: Abbeville Press.

\section{Catalogues}

McKeever, I, (1996), Paintings 1990 - 1996, Angel Row Gallery. 
